Ana Carina da Cunha ${ }^{1}$

Maria Yvone Chaves Mauro ${ }^{2}$

\section{Educação Continuada e a Norma Regulamentadora 32: utopia ou realidade na enfermagem?}

\author{
Continuing Education Program and Brazilian Regulatory \\ Standard-32 - dream or reality in nursing?
}

${ }^{1}$ Enfermeira do Trabalho e Sanitarista. Mestranda da Faculdade de Enfermagem da Universidade do Estado do Rio de Janeiro (UERJ), Rio de Janeiro, RJ.

${ }^{2}$ Professora Visitante Titular da Faculdade de Enfermagem da Universidade do Estado do Rio de Janeiro (FENF/UERJ), Rio de Janeiro, RJ.

Contato:

Ana Carina da Cunha

E-mail:

anarjcunha@gmail.com

\section{Resumo}

A pesquisa, realizada em 2009, foi de natureza descritiva e de análise quantitativa de dados sobre a aplicabilidade da Norma Regulamentadora 32 (NR-32), do Ministério do Trabalho e Emprego (MTE), para responder à questão: Qual a relação entre o programa de Educação Continuada e o processo de implantação de medidas de proteção à segurança e à saúde dos trabalhadores referentes à NR-32 em um hospital público do Rio de Janeiro? Os objetivos foram: descrever o treinamento oferecido pelo Programa de Educação Continuada na instituição, segundo os trabalhadores de enfermagem, e analisar como este treinamento pode influenciar na implantação da NR-32 no hospital. Os resultados mostraram que: $61 \%$ não receberam treinamento antes de iniciar suas atividades; $39,6 \%$ declaram não haver treinamento de forma contínua na instituição; $32 \%$ não foram treinados durante o trabalho, e 46,3\% não receberam ou desconheciam informações, por escrito, sobre riscos biológicos. Os dados indicaram a necessidade de treinamento e formação específica na NR-32 como importantes estratégias de implantação das medidas de proteção à saúde dos trabalhadores.

Palavras-chave: legislação em saúde; educação continuada/permanente; enfermagem.

\section{Abstract}

This is a research conducted in 2009 with descriptive and quantitative analyses of data on the applicability of the Regulatory Standard-32 (NR-32) from the Ministry of Labor and Employment (MTE). We investigated the relationship between the Continuing Education Program and the implementation of health and safety measures for workers, referred in NR-32 in a public hospital in Rio de Janeiro. This article presents the Continuing Education Program offered in this institution from the point of view of the nursing staff, and analyzes how this training affects the implementation of the NR-32 in the hospital. Results showed that $61 \%$ received no training before their start there; $39.6 \%$ reported there was no continuing training in the hospital; $32 \%$ that they were not trained during working hours, and $46.3 \%$ that they had not received any written information about biological hazards. Data indicated that a specific training on the NR-32 is necessary, as an important strategy for implementation of workers safety measures.

Keywords: health legislation; continuing education; nursing. 


\section{Introdução}

A presente pesquisa é sobre a aplicabilidade da Norma Regulamentadora 32 (NR-32), do Ministério do Trabalho e Emprego. Esta Norma emergiu pela solicitação de entidades representativas das diversas categorias de profissionais da saúde, através de vários movimentos, como o Projeto Semente da Saúde - NR-32, da Federação dos Trabalhadores da Saúde do Estado de São Paulo, que sentiram a necessidade de uma legislação específica sobre a exposição ocupacional neste serviço, que antes era fragmentada nas mais diversas legislações do país e não específica para a saúde (FEDERAÇÃO DOS TRABALHADORES DO ESTADO DE SÃO PAULO, 2003; ROBAZZI; MARZIALE, 2004; BRASIL, 2005).

Entre os trabalhadores da área da saúde, há os de enfermagem, que se constituem na maior força de trabalho nos ambientes hospitalares, onde as situações de risco são comuns (SOUZA; VIANNA, 1993; ROBAZZI; MARZIALE, 2004) e os riscos variados, tais como físicos, químicos, biológicos, ergonômicos e de acidentes (MAURO et al., 2004).

Preocupado com esta situação, o Ministério do Trabalho e Emprego constituiu um grupo técnico para elaborar uma normatização que favorecesse os trabalhadores da área da saúde, o que se concretizou no texto original da NR-32 (ROBAZZI; BARROS JUNIOR, 2005; ROBAZZI; MARZIALE, 2004). Após ser encaminhada à Consulta Pública e com todas as sugestões recebidas, o mesmo Ministério constituiu a Comissão Tripartite Paritária Permanente (CTPP), que discutiu e aprovou o texto final da NR assinada pelo Ministro do Trabalho e Emprego (ROBAZZI; BARROS JÚNIOR, 2005).

Em novembro de 2005, o Ministério do Trabalho e Emprego, através da Portaria no 485 , aprovou esta nova Norma Regulamentadora, que recebeu o $\mathrm{n}^{\mathrm{o}} 32$, a qual trata da segurança e saúde no trabalho em serviços de saúde. A partir desta publicação, os serviços de saúde tiveram um prazo máximo de 17 meses para o cumprimento de todos os itens presentes na Norma. Este prazo foi expirado em abril de 2007 (BRASIL, 2005). Contudo, estudos recentes apontam que nem todos os serviços de saúde atenderam suficientemente a NR-32, pois ainda encontramos dados que evidenciam o despreparo dos profissionais e a ocorrência de acidentes de trabalho (RIBEIRO et al., 2009; SIMÃO et al., 2010).

A CTPP também foi criada através da Portaria do Ministério do Trabalho e Emprego no 485, item 32.11.3, da NR-32, e tem por objetivo acompanhar a implementação da Norma e propor adequações necessárias ao aperfeiçoamento da mesma (BRASIL, 2005).

Desde a Primeira Reunião Ordinária da Comissão, que aconteceu nos dias 15 e 16 de março de 2007, ficou evidente a preocupação de todos os representantes sobre a aplicabilidade desta Norma no setor público, fato este registrado na Ata de Reunião (COMISSÃO TRIPARTITE PERMANENTE NACIONAL DA NR-32,
2007). Esta preocupação já era uma constante desde os encontros do GTT-NR-32, que construiu e aprovou o texto inicial da NR-32 (BRASIL, 2004).

Esta norma apresenta grande relação com a educação continuada e a capacitação dos profissionais da área de saúde. O seu item 32.2.4.9 e subitens 32.2.4.9.1 e 32.2.4.9.2 se referem às medidas de proteção, onde há referências sobre a capacitação relacionada aos riscos biológicos que deve acontecer antes do início das atividades e de forma continuada. A capacitação deve ser ministrada durante a jornada de trabalho por profissionais de saúde familiarizados com os riscos inerentes a agentes biológicos e sempre que ocorrer uma mudança das condições de exposição dos trabalhadores a esses agentes. O item 32.2.4.17, por sua vez, está relacionado à vacinação (BRASIL, 2005).

Nos demais itens, a capacitação profissional também é mencionada de forma sistematizada no decorrer do texto, como nos itens 32.3.6 e 32.3.10, que se referem à capacitação relacionada aos riscos químicos; no item 32.4.6, que fala sobre as radiações ionizantes; no item 32.4.14.2.4, sobre braquiterapia; no 32.8.1 e no 32.8.1.1, sobre limpeza e conservação; e por último no item 32.9.1, que trata da manutenção de máquinas e equipamentos. Neste artigo trataremos da capacitação dos profissionais de enfermagem relacionada ao trabalho realizado dentro do ambiente hospitalar, especificamente a exposição ocupacional aos riscos biológicos (BRASIL, 2005).

No ano de 2008 foi publicado o primeiro manual da NR-32 que trata dos riscos biológicos. Esse guia técnico tem por objetivo trazer subsídios a empregadores, trabalhadores e técnicos da área de saúde para uma melhor compreensão e aproveitamento da NR-32, publicada em 2005. Esse material foi produzido por meio de discussões e consensos do grupo tripartite da Comissão Nacional Permanente da NR-32 (BRASIL, 2005, 2008).

Portanto, a exposição ocupacional constante e a dificuldade de implantação dessa norma, principalmente nos hospitais públicos, justificaram a realização deste estudo.

Sabe-se que a prática e o conhecimento atualizado são os fatores mais influentes na aprendizagem e nas mudanças educacionais, que podem ser reforçados pela especialização clínica, criando no funcionário as necessidades de adaptação e reorientação em suas atividades (DAVIM; TORRES; SANTOS, 1999). Isto remete à educação continuada como uma importante estratégia na implantação da NR-32 dentro dos hospitais.

A educação continuada é um:

[...] conjunto de práticas educacionais que visam melhorar e atualizar a capacidade do indivíduo, oportunizando o desenvolvimento do funcionário e sua participação eficaz na vida institucional. (DILLY; JESUS, 1995, p. 92) 
Ao mesmo tempo em que ocorre uma atualização cotidiana das práticas em saúde, segundo os mais recentes aportes teóricos, metodológicos, científicos e tecnológicos disponíveis, insere-se uma necessária construção de relações e processos que passam pelo interior das equipes em atuação conjunta, considerando os agentes, as práticas organizacionais, a instituição e/ou o setor da saúde e as práticas interinstitucionias e/ou intersetoriais, as quais implicam em políticas que se inscrevem nos atos de saúde (CECCIM, 2005).

Neste sentido, questiona-se:

- Qual a relação entre o programa de Educação Continuada e o processo de implantação da Norma Regulamentadora-32, em um hospital público do Rio de Janeiro?

Para atender esta questão de pesquisa, foram elaborados os seguintes objetivos:

1- Descrever o treinamento oferecido pela Educação Continuada, nesta instituição, segundo os trabalhadores de enfermagem;

2- Analisar como este treinamento pode influenciar na implantação da Norma Regulamentadora 32 na instituição.

\section{Metodologia}

Estudo de natureza descritiva, com análise quantitativa dos dados, desenvolvido em um hospital público estadual do Rio de Janeiro.

A coleta foi realizada nos blocos clínico e cirúrgico que são divididos em enfermarias de clínica médica, cirúrgica e ortopédica, com 59 leitos.

A população foi composta por 138 trabalhadores de enfermagem, entre auxiliares de enfermagem, técnicos de enfermagem e enfermeiros com diferentes vínculos empregatícios, pois nesta instituição existem estatutários contratados pela FESP-RJ (Fundação Escola de Serviço Público) e funcionários cooperativados. Num total de 204 trabalhadores, 13 sujeitos estavam de férias, 13 de licença-médica, 3 de licença especial e 37 não concordaram em participar do estudo durante o período de coleta de dados.

Os critérios de inclusão adotados foram profissionais lotados nas enfermarias de clínica médica, clínica cirúrgica e ortopédica, que aceitaram participar da pesquisa e assinaram o Termo de Consentimento Livre e Esclarecido, fornecido juntamente com o questionário.

Portanto, foram excluídos do estudo os profissionais que não se enquadraram nos critérios de inclusão, ou seja, que se recusaram a participar do estudo ou estavam de licença, de férias ou foram remanejados para outros setores diferentes dos previstos como local de estudo.
Com relação ao cargo exercido dentro da instituição, a população foi de 33 participantes enfermeiros, 47 técnicos de enfermagem, 91 auxiliares de enfermagem. Destes 171 profissionais que estavam de serviço, 138 responderam o instrumento. Quando questionados sobre a formação profissional, 21\% possuíam nível superior, 38\% formação técnica e 41\% eram auxiliares de enfermagem, evidenciando que muitos dos participantes possuíam cargo na instituição diferente ao da sua formação profissional.

Pôde-se perceber que alguns técnicos de enfermagem exerciam, neste hospital, a função de auxiliar de enfermagem, assim como alguns enfermeiros exerciam a função de técnicos de enfermagem. Este fato é possível de acontecer na enfermagem por ser uma profissão com várias categorias, sendo comum o profissional iniciar a carreia como auxiliar e depois se aperfeiçoar na profissão com o curso técnico e o superior.

O projeto de pesquisa foi aprovado pelo Comitê de Ética em Pesquisa do Hospital Universitário Pedro Ernesto, com número de protocolo 2260/2008, e a coleta de dados autorizada pela Secretaria Estadual de Saúde do Rio de Janeiro. Todos os participantes assinaram o Termo de Consentimento Livre e Esclarecido

Utilizou-se um questionário estruturado com 90 perguntas fechadas, no período de 28 de janeiro a 14 de fevereiro de 2009, elaborado a partir de um estudo aprofundado da NR-32 (BRASIL, 2005), em coerência com a prática de enfermagem nas enfermarias. Este foi composto pelos seguintes itens: Perfil dos Profissionais (7 questões); Programa de Saúde Ocupacional (4 questões); Espaço Físico e Equipamentos (13 questões); Vestimenta e Capacitação Profissional (11 questões); Riscos Biológicos (18 questões); Vacinação (7 questões); Riscos Químicos (10 questões); Radiações Ionizantes (3 questões); Resíduos de Saúde (9 questões); e Posto de Trabalho e Condições de Conforto (8 questões).

O instrumento foi avaliado por professores peritos em saúde do trabalhador e com vivência hospitalar. O pré-teste foi realizado com 4 auxiliares de enfermagem, 4 técnicos de enfermagem e 10 enfermeiros de outras instituições.

Este artigo refere-se aos resultados e às análises de 4 questões relacionadas à formação profissional, à capacitação profissional e ao treinamento e 3 referentes aos riscos biológicos.

Um segundo questionário com 8 perguntas fechadas relacionadas ao treinamento foi respondido pelo profissional responsável pelo Programa de Educação Continuada a fim de gerar subsídios para a adequada discussão dos resultados da pesquisa.

Os resultados foram organizados e analisados a fim de atender aos objetivos deste estudo com o auxílio dos programas estatísticos: Statical Package for the Social Sciences (SPSS), versão 13 for Windows e Microsoft Office Excel 2003. 


\section{Resultados e discussão}

\section{Atuação da Educação Continuada segundo os profis- sionais de enfermagem}

A enfermagem é uma profissão que requer constante atualização devido à evolução tecnológica e científica. Nesse sentido, utiliza, muitas vezes, o serviço de Educação Continuada para oferecer aos seus funcionários conhecimentos para uma atuação eficaz (SOUZA; CERIBELLI, 2004).

Nesta instituição, apenas um profissional do Programa de Educação Continuada é responsável pelo treinamento dos trabalhadores de enfermagem e não há uma integração com a Comissão de Controle de Infecções Hospitalares e o Serviço de Saúde Ocupacional para treinamento de pessoal, como é preconizado pela NR-32.

O Programa de Educação Continuada oferece treinamento continuado e sistemático com registro de presença dos participantes. Porém, não é abrangente a todos os plantões.

O Serviço de Saúde Ocupacional é inexistente na unidade, sendo apenas oferecidos serviços médicos ambulatoriais por especialidades médicas que caracterizam o Núcleo de Atenção e Promoção à Saúde do Servidor (Nuaps).

As atividades relacionadas à saúde do trabalhador, em algumas unidades de saúde do Estado, ficam concentradas e são oferecidas num serviço centralizado.
A Tabela 1 mostra os dados relativos à disponibilidade e ao funcionamento dos programas de treinamento oferecidos pela Educação Continuada, na instituição pesquisada, de acordo com a categoria profissional.

Os resultados apontaram que 61\% dos participantes mencionaram não ter tido qualquer tipo de treinamento antes do início de suas atividades e, caso existisse um programa de treinamento de Educação Continuada (EC) dentro do hospital, 26,5\% dos profissionais desconheciam.

Sabe-se que os problemas existentes na formação e no exercício dos profissionais na área da saúde devem ser situados no contexto político-econômico e social, exigindo mudanças curriculares, organizacionais, reestruturações das práticas, bem como o engajamento nas lutas por condições mais favoráveis de trabalho (SORDI; BAGNATO, 1998).

De acordo com a NR-32, a capacitação dos profissionais de saúde deve ocorrer sempre antes do início das atividades e de forma continuada, ministrada por profissionais capacitados e familiarizados com os riscos inerentes a cada local de trabalho e com a condição de exposição ocupacional. Incluem-se nesta análise: riscos potenciais para a saúde, medidas de controle, normas e procedimentos de higiene, equipamentos de proteção individual e coletiva, vestimentas adequadas ao trabalho, medidas de prevenção de acidentes e incidentes e medidas a serem adotadas na ocorrência dos mesmos (BRASIL, 2005).

Tabela 1 Distribuição das variáveis relacionadas ao treinamento entre as categorias profissionais, Rio de Janeiro/RJ, 2009

\begin{tabular}{|c|c|c|c|c|}
\hline Variáveis & $\begin{array}{c}\text { Auxiliar } \\
n(\%)\end{array}$ & $\begin{array}{c}\text { Técnico } \\
n(\%)\end{array}$ & $\begin{array}{c}\text { Enfermeiro } \\
n(\%)\end{array}$ & $\begin{array}{l}\text { Total } \\
n(\%)\end{array}$ \\
\hline \multicolumn{5}{|c|}{$\begin{array}{l}\text { Há treinamento de funcionários antes do } \\
\text { início das atividades }\end{array}$} \\
\hline Sempre & $2(3,6)$ & $2(3,8)$ & $0(0,0)$ & $4(2,9)$ \\
\hline Às vezes & $3(5,5)$ & $4(7,7)$ & $6(20,7)$ & $13(9,6)$ \\
\hline Nunca & $30(54,5)$ & $36(69,2)$ & $17(58,6)$ & $83(61,0)$ \\
\hline Desconhece & $20(36,4)$ & $10(19,2)$ & $6(20,7)$ & $36(26,5)$ \\
\hline Total & $55(100,0)$ & $52(100,0)$ & $29(100,0)$ & $136(100,0)^{*}$ \\
\hline \multicolumn{5}{|l|}{ O treinamento ocorre: } \\
\hline \multicolumn{5}{|l|}{ a) De forma continuada } \\
\hline Sempre & $1(1,9)$ & $2(3,8)$ & $0(0,0)$ & $3(2,2)$ \\
\hline Às vezes & $15(28,3)$ & $13(25,0)$ & $15(51,7)$ & $43(32,1)$ \\
\hline Nunca & $17(32,1)$ & $25(48,1)$ & $11(37,9)$ & $53(39,6)$ \\
\hline Desconhece & $20(37,7)$ & $12(23,1)$ & $3(10,3)$ & $35(26,1)$ \\
\hline Total & $53(100,0)$ & $52(100,0)$ & $29(100,0)$ & $133(100,0)^{*}$ \\
\hline \multicolumn{5}{|c|}{ b) Durante a jornada de trabalho } \\
\hline Sempre & $6(11,8)$ & $6(13,0)$ & $2(7,1)$ & $14(11,2)$ \\
\hline Às vezes & $14(27,5)$ & $11(23,9)$ & $11(39,3)$ & $36(28,8)$ \\
\hline Nunca & $14(27,5)$ & $17(37,0)$ & $9(32,1)$ & $40(32,0)$ \\
\hline Desconhece & $17(33,3)$ & $12(26,1)$ & $6(21,4)$ & $35(28,0)$ \\
\hline Total & $51(100,0)$ & $46(100,0)$ & $28(100,0)$ & $125(100,0)^{*}$ \\
\hline
\end{tabular}

*As diferenças nos valores absolutos das frequências correspondem a perdas. 
O treinamento inicial na admissão do profissional, se implantado em todos os serviços de saúde, poderia reduzir consideravelmente os acidentes relacionados aos materiais biológicos que prevalecem no ambiente hospitalar (SARQUIS; FELLI, 2000; JORGE et al., 2000; NISHIDE; BENATTI; ALEXANDRE, 2004). Este treinamento pode ser composto de revisões técnicas, administrativas e de acompanhamento por supervisão direta (KOIZUMI et al., 1998; SIQUEIRA; KURCGANT, 2005).

Estudo transversal sobre acidentes de trabalho envolvendo exposição a material biológico, ocorridos em hospital de Brasília, apontaram que as estratégias preventivas utilizadas, como treinamento, visitas de inspeção aos locais de trabalho e orientações individuais, devem ser reformuladas e embasadas em métodos educativos e de promoção à saúde ocupacional, centrados não só na prevenção de acidentes, mas na melhoria da qualidade de vida no trabalho (MARZIALE, et al., 2007).

O treinamento deve acontecer no horário de trabalho e pode ser acompanhado pelo enfermeiro da própria unidade. Cabe ele, como parte integrante da equipe, a participação em programas de treinamento e aprimoramento do pessoal de saúde, desde que seja devidamente capacitado (THOFEHRN; MUNIZ; SILVA, 2000; BRASIL, 2005).

Os resultados, ainda, revelaram que para 39,6\% dos trabalhadores este treinamento não ocorreu de forma continuada e $32 \%$ declararam que as atividades relacionadas ao treinamento e à capacitação oferecidos nunca aconteceram durante a jornada de trabalho, dificultando a sua participação.
Sabe-se que, desde 2005, quando entrou em vigência a NR-32, toda a capacitação deve ser documentada com registro de data, horário, carga horária, conteúdo ministrado, nome e formação ou capacitação profissional do instrutor e dos trabalhadores envolvidos para fins de comprovação junto ao Ministério do Trabalho e Emprego (BRASIL, 2005).

\section{A Educação Continuada e a implantação da NR-32}

O Gráfico 1 demonstra a distribuição percentual de respostas relativas à divulgação e ao treinamento sobre a NR-32, por categoria profissional.

Pode-se perceber, neste estudo, que 72 participantes desconhecem qualquer tipo de divulgação ou a existência de treinamento oferecido pelo hospital que estivesse relacionado à NR-32. Dentre estes, 36,5\% eram enfermeiros, 57,7\% técnicos de enfermagem e $66,7 \%$ auxiliares de enfermagem. Dos 28 enfermeiros que responderam à esta questão, 60,7\% nunca receberam qualquer treinamento ou capacitação relacionados ao assunto.

Este fato está relacionado diretamente ao Programa de Educação Continuada, em que somente um profissional fica responsável pelo treinamento. Segundo ele, não houve treinamento formal específico sobre a NR-32 na instituição.

Com relação aos demais temas abordados na realização de palestras e cursos oferecidos pela Educação Continuada, a inscrição prévia para participação possui quantitativo razoável, porém o comparecimento dos profissionais é bem reduzido.

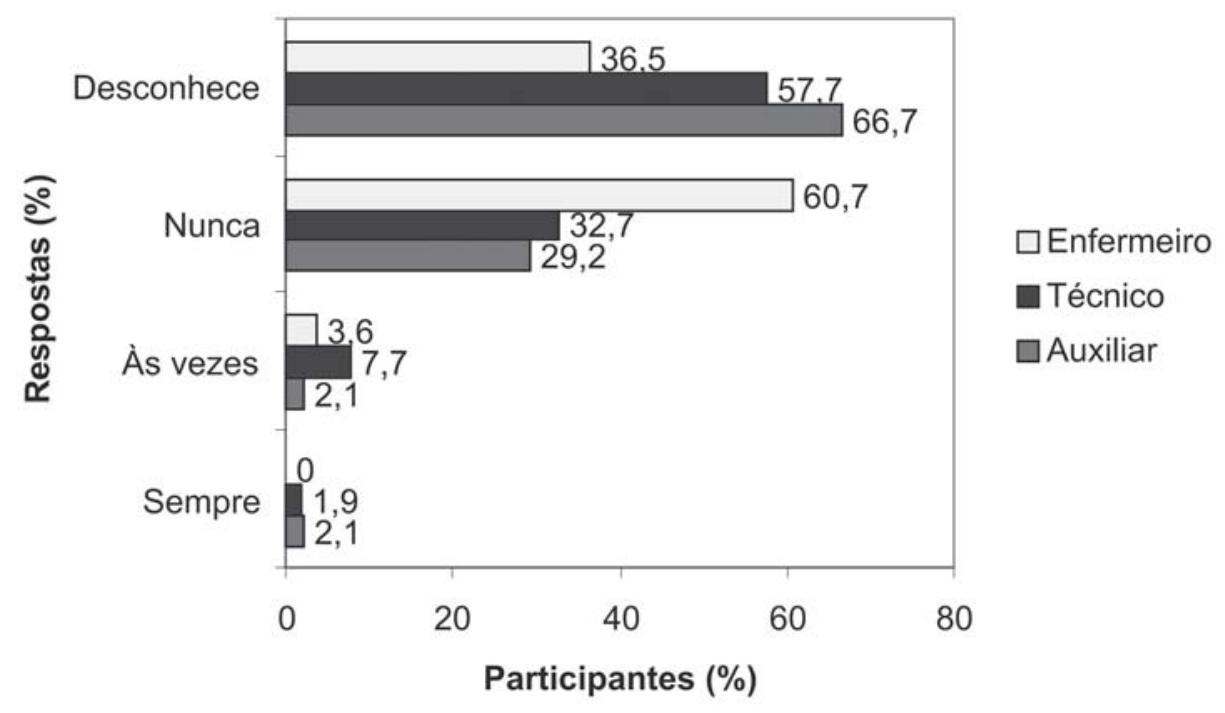

Gráfico 1 Distribuição percentual de respostas relativas à divulgação ou ao treinamento na instituição sobre a NR-32 entre as categorias profissionais, Rio de Janeiro/RJ, 2009 
A NR-32 prevê que, em todo local onde exista a possibilidade de exposição a agentes biológicos, devem ser fornecidas aos trabalhadores instruções escritas, em linguagem acessível, das rotinas realizadas no local de trabalho, das medidas de prevenção de acidentes e doenças relacionadas ao trabalho. Estas instruções devem ser entregues ao trabalhador, mediante recibo, devendo este ficar à disposição da inspeção pelo Ministério do Trabalho (BRASIL, 2005 e 2008).

Na Tabela 2, pode-se verificar as variáveis relacionadas ao treinamento e à exposição aos riscos biológicos entre os profissionais de enfermagem.

Nesta pesquisa, os resultados revelaram que, dentre os profissionais de enfermagem, 41,2\% alegaram que às vezes são fornecidas, por escrito, informações relativas à possibilidade de exposição ocupacional, assim como 57,1\% dos participantes também referiram que às vezes são remanejados para outros setores. Porém, quando remanejados, 67,2\% nunca receberam treinamento específico.

Segundo a atual legislação, o empregador deve assegurar a capacitação dos trabalhadores sempre que ocorrer uma mudança das condições de exposição dos trabalhadores aos agentes biológicos (BRASIL, 2005).

De acordo com Thofehrn, Muniz e Silva (2000), os programas da educação continuada sempre ocorreram de forma empírica, sem a realização de um diagnóstico, o qual possibilitaria a elaboração de um programa voltado às necessidades da população-alvo. Através deste diagnóstico, pode-se realizar um levantamento das reais necessidades e expectativas do grupo de trabalho frente à temática em pauta. Este trabalho poderia gerar maior interesse dos trabalhadores e assegurar o comparecimento de profissionais nos treinamentos oferecidos pela Educação Continuada da instituição pesquisada.

O estabelecimento de um programa interdisciplinar de educação continuada propicia maior integração da equipe de saúde, promovendo oportunidades de aprendizagem e intercâmbio de conhecimentos (THOFEHRN; MUNIZ; SILVA, 2000).

Em pesquisa realizada no setor de emergência deste hospital, em 2005, envolvendo profissionais de enfermagem, foi constatado que alguns fatores influenciavam na falta de conhecimento dos trabalhadores de enfermagem acerca dos riscos biológicos. Dentre estes, os mais citados foram: o pouco interesse pessoal, a falta de estímulo para seu crescimento pessoal, disponibilidade de tempo, sobrecarga de trabalho, falta de oferta de cursos/treinamentos em horários alternativos, disponibilidade de equipamentos de proteção individual (EPIs) em quantitativo insuficiente, com qualidade e tamanho inadequados às características antropométricas dos funcionários, falta de treinamento e desconhecimento do mecanismo de transmissão das doenças infectocontagiosas (CUNHA; VALENTE, 2005).

Tabela 2 Distribuição das variáveis relacionadas ao treinamento e à exposição aos riscos biológicos entre as categorias profissionais, Rio de Janeiro/RJ, 2009

\begin{tabular}{|c|c|c|c|c|}
\hline Variáveis & $\begin{array}{c}\text { Auxiliar } \\
n(\%)\end{array}$ & $\begin{array}{c}\text { Técnico } \\
n(\%)\end{array}$ & $\begin{array}{c}\text { Enfermeiro } \\
n(\%)\end{array}$ & $\begin{array}{l}\text { Total } \\
n(\%)\end{array}$ \\
\hline \multicolumn{5}{|c|}{$\begin{array}{l}\text { São fornecidas informaç̃oes, por escrito, sobre a } \\
\text { possibilidade de exposição aos riscos biológicos }\end{array}$} \\
\hline Sempre & $9(16,1)$ & $4(7,8)$ & $4(13,8)$ & $17(12,5)$ \\
\hline Às vezes & $26(46,4)$ & $19(37,3)$ & $11(37,9)$ & $56(41,2)$ \\
\hline Nunca & $15(26,8)$ & $15(29,4)$ & $9(31,0)$ & $39(28,7)$ \\
\hline Desconhece & $6(10,7)$ & $13(25,5)$ & $5(17,2)$ & $24(17,6)$ \\
\hline Total & $56(100,0)$ & $51(100,0)$ & $29(100,0)$ & $136(100,0)^{*}$ \\
\hline \multicolumn{5}{|c|}{ É remanejado para outro setor de trabalho } \\
\hline Sempre & $4(7,4)$ & $5(9,8)$ & $0(0,0)$ & $9(6,8)$ \\
\hline Às vezes & $29(53,7)$ & $32(62,7)$ & $15(53,6)$ & $76(57,1)$ \\
\hline Nunca & $13(24,1)$ & $6(11,8)$ & $8(28,6)$ & $27(20,3)$ \\
\hline Desconhece & $8(14,8)$ & $8(15,7)$ & $5(17,9)$ & $21(15,8)$ \\
\hline Total & $54(100,0)$ & $51(100,0)$ & $28(100,0)$ & $133(100,0)^{\prime \prime}$ \\
\hline \multicolumn{5}{|c|}{ Quando muda de setor, você recebe treinamento } \\
\hline Sempre & $1(1,9)$ & $1(2,0)$ & $2(7,1)$ & $4(3,1)$ \\
\hline Às vezes & $2(3,7)$ & $4(8,2)$ & $3(10,7)$ & $9(6,9)$ \\
\hline Nunca & $36(66,7)$ & $36(73,5)$ & $16(57,1)$ & $88(67,2)$ \\
\hline Desconhece & $15(27,8)$ & $8(16,3)$ & $7(25,0)$ & $30(22,9)$ \\
\hline Total & $54(100,0)$ & $49(100,0)$ & $28(100,0)$ & $131(100,0)^{*}$ \\
\hline
\end{tabular}

*As diferenças nos valores absolutos das frequências correspondem a perdas. 
A própria evolução tecnológica traz modificações na organização do trabalho, o que exige constante atualização de conhecimentos por parte dos trabalhadores. Aliados a este avanço tecnológico estão o progressivo processo de conscientização da população e também os fatores internos, como a consciência sobre necessidades pessoais e profissionais de aprendizagem pelos próprios profissionais, e que determinam a necessidade de educação continuada (MONTEIRO; CHILLIDA; BARGAS, 2004).

Com relação aos fatores internos, a Educação Continuada precisa ser um instrumento para despertar a consciência dos profissionais envolvidos, a ponto de motivá-los a se aprimorar e a se transformar profissionalmente, e não mais trabalhar apenas de forma a buscar o cumprimento de suas atividades (AZAMBUJA; KERBER; VAZ, 2001).

\section{Conclusões}

Constatou-se que uma parcela significativa dos sujeitos não recebeu qualquer treinamento antes do início de suas atividades, num ambiente de trabalho onde os riscos ocupacionais são inúmeros. Quando este foi oferecido, não ocorreu durante a jornada de trabalho e sim de forma descontínua para mais de um terço dos casos.

Estes fatos podem ser compreendidos pela necessidade de mais profissionais envolvidos no Programa de Educação Continuada, visto que os treinamentos não abrangem todos os plantões, apesar de ser sistemático e continuado com treinamentos semanais. Vale ressaltar que, no hospital onde aconteceu o estudo havia apenas uma enfermeira responsável por todo o programa de Educação Continuada, sem nenhum tipo de interação com a CCIH ou o Serviço de Saúde Ocupacional para lhe dar apoio.

Portanto, a maioria desconhecia se o Programa de Educação Continuada oferecia algum tipo de treinamento ou divulgação dos itens relativos à NR-32. E somente uma minoria recebeu informações, por escrito, sobre riscos biológicos, embora muitos já tenham sido remanejados sem qualquer tipo de treinamento.

Notou-se que o treinamento oferecido para os profissionais de enfermagem pela Educação Continuada desta instituição de saúde não corresponde ao recomendado pela Norma e, da forma como foi realizado, não contribuiu adequadamente para sua implantação. Isso ratifica fatos apontados por outros pesquisadores em estudos anteriores, segundo os quais os treinamentos ficam sob a responsabilidade de uma só equipe dentro da instituição, que oferecem treinamentos com temas empíricos e teóricos, mas que, muitas vezes, não representam as reais necessidades dos trabalhadores. O que nos remete a profissionais desqualificados para o trabalho e à ocorrência dos acidentes de trabalho.

As dificuldades da instituição e do Programa de Educação Continuada acima relatadas devem ser levadas em consideração e sanadas o mais breve possível para a realização de um trabalho efetivo, além de haver a necessidade da realização de interação entre o trabalho da Educação Continuada e CCIH e a implantação de um Serviço de Saúde Ocupacional. O trabalho realizado de forma isolada, sem a participação dos demais programas dentro do hospital e a atuação efetiva dos trabalhadores não é capaz de gerar mudanças e despertar a consciência quanto a sua própria saúde.

Os dados apontaram dificuldade no cumprimento da legislação em vigor no país e a importância da atuação da Educação Continuada para a implantação da NR-32, através da sua divulgação e de implantação de estratégias preventivas.

Sabe-se que, em se tratando de legislação, há a necessidade da implantação, sendo uma das primeiras etapas a divulgação de sua existência e de seu conteúdo, seguida de fiscalização para que seja cumprida, tanto por parte do empregador, quanto do trabalhador. Porém, com relação à NR-32 é fundamental o despertar de consciência sobre sua importância para a área de saúde. Esta construção de conhecimento deve ser realizada de forma conjunta com todos os profissionais para que não seja transformada em mero cumprimento de leis ou normas como tantas outras existentes no país.

Apesar dos resultados obtidos não apresentarem diferenças estatisticamente significativas, eles mostraram a realidade destes setores do hospital e a necessidade de realização de estudos complementares, extensivos aos demais setores dos hospitais públicos. Visa-se, desta forma, promover o conhecimento global da situação de trabalho e a elaboração de estratégias eficazes para a implantação da NR-32, com a responsabilidade da Direção do Hospital e a participação ativa do Programa de Educação Continuada em conjunto com a CCIH e o Serviço de Saúde Ocupacional a fim de transformar esta utopia em uma realidade para a enfermagem.

\section{Contribuições de autoria}

As duas autoras construíram o projeto de pesquisa, coletaram e analisaram os dados e contribuíram para a redação do artigo. 


\section{Referências}

AZAMBUJA, E. P.; KERBER, N. P. C.; VAZ, M. R. C. O trabalho da enfermagem: um espaço de construção da prevenção do risco e acidente de trabalho. Texto $\mathcal{E}$ Contexto Enfermagem, Florianópolis, v. 10, n. 1, p. 7593, jan./abr. 2001.

BRASIL. Ministério do Trabalho e Emprego. Ata da $2^{2}$ reunião ordinária de 01 de julho de 2004. Brasília, 2004. Disponível em: <http:/www.mte.gov.br/seg sau/grupos_gtnr32_atas01072004.asp >. Acesso em: 18 abr. 2008.

Ministério do Trabalho e Emprego. Portaria $\mathrm{n}^{\mathrm{o}}$ 485, de 11 de Novembro de 2005. NR 32 - Segurança e Saúde no Trabalho em Serviços de Saúde. Diário Oficial [da] República Federativa do Brasil, Brasília, DF, 16 nov. 2005. Disponível em: <http://www.mte.gov. br/legislaçao/normas_regulamentadoras/nr_32.pdf $>$. Acesso em: 18 abr. 2008.

Ministério do Trabalho e Emprego. Riscos biológicos: guia técnico - os riscos biológicos no âmbito da norma regulamentadora № 32. Brasília, DF, 2008.

CECCIM, R. B. Educação permanente em saúde: desafio ambicioso e necessário. Interface -

Comunicação, Saúde, Educação, Botucatu, v. 9, n. 16, p. 161-77, set./fev. 2005.

COMISSÃO TRIPARTITE PERMANENTE NACIONAL DA NR-32. São Paulo. Ata da $1^{\underline{a}}$ reunião ordinária. Brasília, 2007. Disponível em: <http://www.mtb.gov. br/seg_sau/comissoes_ctpn_atas.pdf $>$. Acesso em: 18 abr. 2008.

CUNHA, A. C.; VALENTE, G. S. C. Desvelando o conhecimento dos trabalhadores de enfermagem acerca dos riscos biológicos na emergência. 2005, 111 f. Trabalho de Conclusão de Curso (Graduação em Enfermagem)-Universidade Estácio de Sá, Rio de Janeiro, 2005.

DAVIM, R. M. B.; TORRES, G. V. SANTOS, S. R. Educação continuada em enfermagem: conhecimentos, atividades e barreiras encontradas em uma maternidade escola. Revista Latino-Americana de Enfermagem, Ribeirão Preto, v. 7, n. 5, dez. 1999.

DILLY, C. M. L.; JESUS, M. C. P. Processo educativo em enfermagem: das concepções pedagógicas à prática profissional. São Paulo: Robe, 1995.

FEDERAÇÃO DOS TRABALHADORES DA SAÚDE DO ESTADO DE SÃO PAULO. NR 32 - projeto semente da saúde: portifólio. São Paulo, 2003.

JORGE, R. et al. Acidentes biológicos em hospital universitário. Revista Médica do Hospital São Vicente de Paulo, Passo Fundo, v. 11, n. 26, p. 19-22, jan./jun. 2000.

KOIZUMI, M. S. et al. Educação continuada da equipe de enfermagem nas UTIs do município de São Paulo.
Revista Latino-Americana de Enfermagem, Ribeirão Preto, v. 6, n. 3, p. 33-41, jul. 1998.

MARZIALE, M. H. P. et al. Acidentes com material biológico em hospital da rede de prevenção de acidentes de trabalho - REPAT. Revista Brasileira de Saúde Ocupacional, São Paulo, v. 32, n. 115, p. 109119, 2007.

MAURO, M. Y. C. et al. Riscos ocupacionais em saúde. Revista Enfermagem Uerj, Rio de Janeiro, v. 12, n. 3, p. 338-345, 2004.

MONTEIRO, M. I.; CHILLIDA, M. S. P.; BARGAS, E. B. Educação continuada em um serviço terceirizado de limpeza de um hospital universitário. Revista LatinoAmericana de Enfermagem, Ribeirão Preto, v. 12, n. 3, p. 541-548, mai./jun. 2004.

NISHIDE, V. M.; BENATTI, M. C. C.; ALEXANDRE, N. M. C. Ocorrência de acidente do trabalho em uma unidade de terapia intensiva. Revista LatinoAmericana de Enfermagem, Ribeirão Preto, v. 12, n. 2, p. 204-211, mar./abr. 2004.

RIBEIRO, A. S. R. et al. Caracterização de acidente com material perfurocortante e a percepção da equipe de enfermagem. Cogitare Enfermagem, Curitiba, v. 14, n. 4, p. 660-666, out./dez. 2009

ROBAZZI, M. L. C. C.; MARZIALE, M.H. A norma regulamentadora 32 e suas implicações sobre os trabalhadores de enfermagem. Revista LatinoAmericana de Enfermagem, Ribeirão Preto, v. 12, n. 5, p. 834-836, set./out. 2004.

ROBAZZI, M. L. C. C; BARROS JÚNIOR, J. C. Proposta brasileira de normatização para os trabalhadores da saúde. Ciência y Enfermeria, Concepción, v. 11, n. 2, p. 11-15, 2005.

SARQUIS, L. M. M.; FELLI, V. E. A. O uso dos equipamentos de proteção individual entre os trabalhadores de enfermagem acidentados com instrumentos perfurocortantes. Revista Brasileira de Enfermagen, Brasília, v. 53, n. 4, p. 564-573, out./ dez. 2000.

SIMÃO, S. A. F. et al. Fatores associados aos acidentes biológicos entre profissionais de enfermagem. Cogitare Enfermagem, Curitiba, v. 15, n. 1, p. 87-91, jan./mar. 2010.

SIQUEIRA, I. L. C. P.; KURCGANT, P. Estratégias de capacitação de enfermeiros recém-admitidos em unidades de internação geral. Revista da Escola de Enfermagem da USP, São Paulo, v. 39, n. 3, p. 251-57, 2005.

SORDI, M. R. L.; BAGNATO, M. H. S. Subsídios para uma formação profissional crítico reflexiva na área da saúde: o desafio da virada do século. Revista LatinoAmericana de Enfermagem, Ribeirão Preto, v. 6, n. 2, p. 83-88, abr. 1998. 
SOUZA, M. C. B.; CERIBELLI, M. I. P. F. Enfermagem no centro de material esterilizado: a prática da educação continuada. Revista Latino-Americana de Enfermagem, Ribeirão Preto, v. 12 n. 5, p. 767-74, set./out. 2004.

SOUZA, M.; VIANNA, L. A. C. Incidência de acidentes de trabalho relacionada com a não utilização das precauções universais. Revista Brasileira de Enfermagem, Brasília, v. 46 n. 3, p. 234-244, 1993.

THOFEHRN, M. B.; MUNIZ, R. M.; SILVA, R. R.

Educação continuada em enfermagem no hospitalescola: um diagnóstico. Revista Brasileira de Enfermagem, Brasília, v. 53, n. 4, p. 524-532, out./dez. 2000. 